\title{
How perception of learning environment predicts male and female students' grades and motivational outcomes in algebra-based introductory physics courses
}

\author{
Sonja Cwik@ and Chandralekha Singh $\odot$ \\ Department of Physics and Astronomy, University of Pittsburgh, Pittsburgh, Pennsylvania 15260, USA
}

(Received 13 August 2021; accepted 4 October 2021; published 20 December 2021)

\begin{abstract}
Student grades and motivational outcomes in introductory physics courses can influence their retention in science, technology, engineering, and mathematics disciplines and future career aspirations. We surveyed students in mandatory large introductory level algebra-based physics courses for bioscience majors at a large research university. The study investigates how students' perception of their learning environment, including their sense of belonging, peer interactions, and perceived recognition by instructors, predicts male and female students' grade, self-efficacy, interest, and identity at the end of physics 2, controlling for their high school GPA and SAT math scores. We find that although women outnumbered men in these courses, women had worse outcomes than men. Moreover, using structural equation modeling, we find that all factors in students' perception of their learning environment are essential to predicting their self-efficacy, interest, grade, and identity at the end of physics 2 . The findings pertaining to gender differences call into question equity in learning in these physics courses and how the perception of the learning environment predicts the outcomes and can be useful for creating an equitable and inclusive learning environment to help all students excel in these algebra-based physics courses.
\end{abstract}

DOI: 10.1103/PhysRevPhysEducRes.17.020143

\section{INTRODUCTION AND THEORETICAL FRAMEWORK}

While prior studies have investigated issues pertaining to women's representation in science, technology, engineering, and math (STEM) fields [1-14], most studies in college physics courses have focused on courses in which women are outnumbered by men. In addition, several studies also reported gender disparity in students' performance in some STEM disciplines [15-17]. In these studies, several factors have been studied that negatively impact women and could lead to their underrepresentation and underperformance. Some of the factors include societal stereotypes and biases about who belongs in these fields as well as the potentially intertwined issue of motivational beliefs, such as self-efficacy, interest, and identity pertaining to STEM disciplines [18-26].

Self-efficacy in a discipline refers to students' belief in their ability to accomplish tasks or solve problems $[27,28]$. Self-efficacy has been shown to impact students' engagement, learning, and persistence in science courses as well as contribute to the students' science identity [18,27,29-34]. For example, when tackling difficult problems, students

Published by the American Physical Society under the terms of the Creative Commons Attribution 4.0 International license. Further distribution of this work must maintain attribution to the author(s) and the published article's title, journal citation, and DOI. with high self-efficacy tend to view the problems as challenges that can be overcome whereas people with low self-efficacy tend to view them as threats to be avoided [27]. Similarly, interest in a particular discipline may affect students' perseverance, persistence, and achievement in STEM courses [32,35-40]. One study showed that changing the curriculum to stimulate the interest of the female students helped improve all of the students' understanding at the end of the year [41]. In Eccles' expectancy-value theory, interest and self-efficacy can influence each other as well as a student's performance in a class $[42,43]$. This is important in physics courses since several studies have shown performance gaps between men's and women's grades and scores on conceptual tests in calculus-based and algebra-based physics courses [44-49]. Some hypothesize that causes of this gender gap include career goals, prior preparation, and motivational beliefs $[14,37,48-56]$.

In addition, self-efficacy and interest have been shown to influence students' identity in STEM courses. Science identity is defined as identifying with academic domains in science, i.e., whether students see themselves as science people or people who can excel in science disciplines [57-59]. Students' identity in STEM disciplines has been shown to play an important role in their in-class participation in related courses and choices of majors and careers [57,60-64]. The science identity framework by Johnson et al. [61] includes three dimensions: competence ("I think I can"), performance ("I am able to do"), and recognition ("I am recognized by others"). Hazari et al. modified the 
framework specifically for physics. "Competence" and "performance" were defined as students' beliefs in their ability to understand the subject and students' belief in their ability to perform physics tasks. Additionally, recognition was framed as recognition by others as being a good physics student. Lastly, a fourth dimension, interest, was added to the framework by Hazari et al. since students have highly varying levels of interest in physics $[65,66]$. Here we use a slightly reframed version of the physics identity framework by Kalender et al. [67]. In particular, performance and competence were combined into a single latent variable, self-efficacy (closely related to competency belief). Studies have shown that it can be more difficult for women to form a physics identity than men $[58,68-70]$. However, most of the studies in the college context concerning physics identity and factors that influence it are conducted in classes in which women are underrepresented [57,71]. According to Gee's identity framework [62], students' identity in a domain can be context dependent. Therefore, it is important to examine the physics identity of students in physics courses in which women outnumber men, e.g., in introductory physics courses for bioscience majors in which women are not underrepresented.

Students in these courses may be influenced by societal stereotypes and biases even before they enter the classroom. One common stereotype is the idea of genius and brilliance are important factors to succeed in physics [72]. However, genius is often associated with boys [73], and girls tend to shy away from fields associated with innate brilliance or genius from a young age [74]. Studies have found that by the age of six, girls are less likely than boys to believe they are "really really smart" and less likely to choose activities that are designed for "brilliant people" [74]. As these students get older, often the norms in the science curriculum tend not to represent the interests and values of girls $[68,75]$. All of these stereotypes and factors can influence female students' perception of their ability to do physics before they enter the classroom. So, it is possible that although women are the majority in algebra-based physics courses, these societal stereotypes can still influence their outcomes in those classes if the learning environment is not equitable and inclusive.

Although other studies have investigated gender differences in motivational beliefs and correlations between students' attitudes and performance in introductory physics courses, most studies have not considered students' perception of the learning environment in influencing their outcomes particularly in courses in which women are not underrepresented. In our study, within the perception of the learning environment, we include students' self-reported sense of belonging, perceived recognition, e.g., by instructors and teaching assistants, and interaction with peers in the class. Students' sense of belonging in physics has been shown to correlate with their retention and self-efficacy $[76,77]$ and students' interaction with peers has been shown to enhance their understanding and engagement in courses [78]. A student's perceived recognition by others has been shown to play an important role in a student's identity [63] and is especially related to women's other motivation beliefs [77]. Studies have shown that female students do not feel recognized appropriately even before they enter college $[68,71,74]$. Our prior individual interviews suggest that students' perceived recognition by instructors and teaching assistants (TAs) impacts their self-efficacy and interest in physics (see, e.g., Refs. [79,80]). In addition, other learning environment factors, such as students' sense of belonging and interaction with their peers, can play a significant role in their learning and motivational outcomes.

This study uses structural equation modeling (SEM) to examine the difference between male and female students on the role of the learning environment in influencing motivational and performance outcomes at the end of a mandatory two-semester algebra-based introductory physics course sequence for bioscience majors, controlling for their high school GPA, SAT math scores, grade, selfefficacy and interest in college physics 1 . We controlled for students' past performance in high school and in the physics 1 course as well as their motivational beliefs when they started the course to try and isolate the effect of the learning environment on student outcomes. In our algebrabased introductory physics courses, $62 \%$ of the enrolled students are women. Even though women are not underrepresented in the algebra-based courses, it is important to investigate their motivational beliefs and performance outcomes since stereotypes about who can excel at physics could still have consequences in these courses.

Combining these important motivational beliefs and outcomes in our study, a visual of our model that focuses on the role of the learning environment is shown in Fig. 1. All regression paths were considered from left to right in our model. However, only some of the paths are shown for clarity. High school factors, SAT math scores, and GPA, as well as outcomes from physics 1 (self-efficacy, interest, and grade), are controlled for at the beginning of the model. We then investigate how the perception of the learning environment (perceived recognition, peer interaction, and belonging) predicts student outcomes at the end of the two-semester physics course sequence (grade, self-efficacy, interest, and physics identity). Our research questions are as follows:

RQ1 Are there gender differences in students' grades and physics motivational beliefs at the end of the mandatory two semester course sequence?

RQ2 Is there moderation (interactions) by gender for any of the regression paths (predictive relationships)?

RQ3 If moderation does not affect any path, does gender mediate

a. the factors that were controlled for?

b. the perception of the physics learning environment controlling for the controlled factors? 


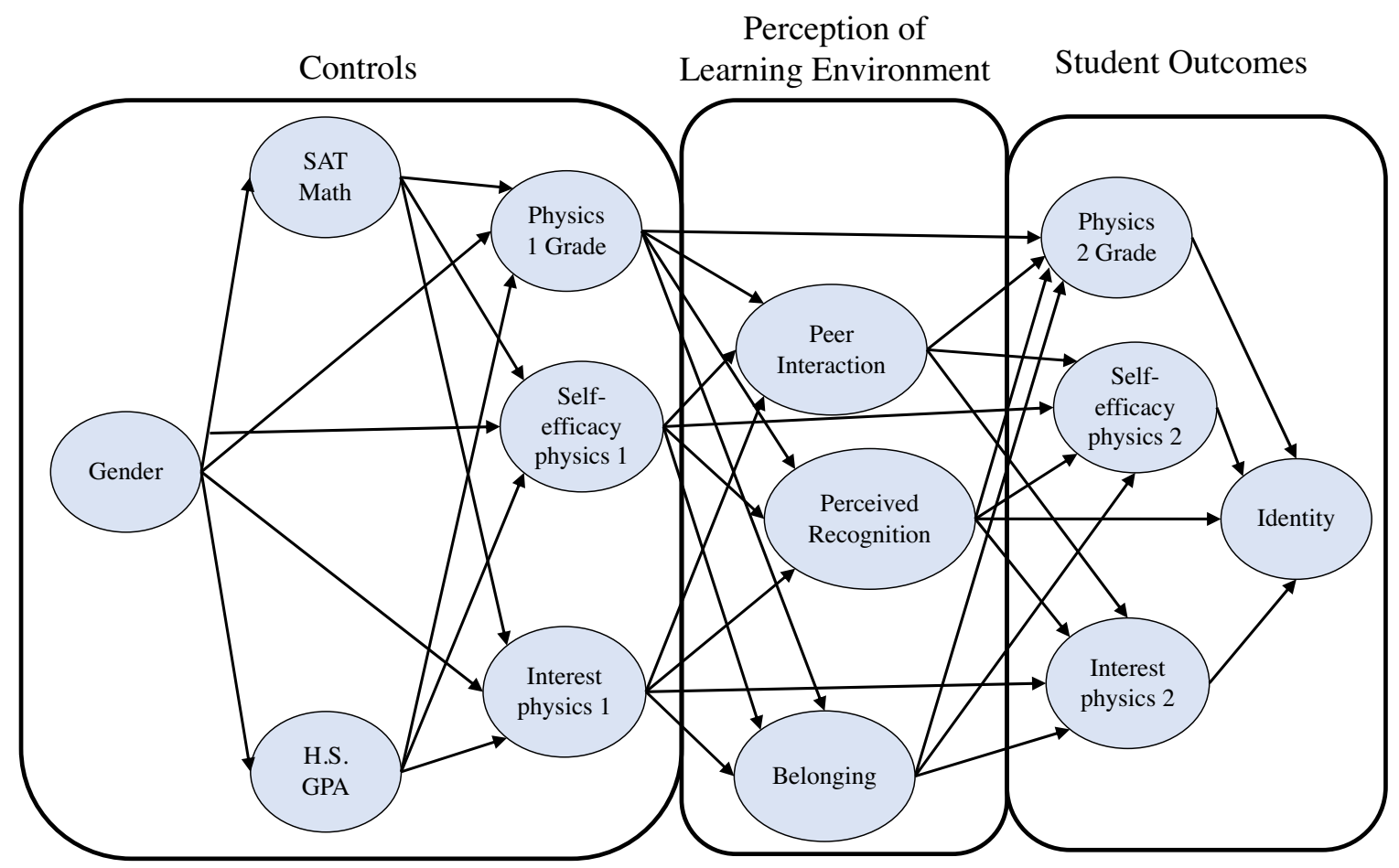

FIG. 1. Schematic representation of the model based on the theoretical framework. From left to right, all possible paths were considered. Some, but not all, of the regression paths are shown (since others were not statistically significant).

c. the student outcomes after controlling for everything else in the model?

RQ4 Which factors, including those in the physics learning environment, post interest, post self-efficacy, and grade at the end of the course, predict physics identity?

RQ5 How does the perception of the physics learning environment predict student outcomes in physics 2, controlling for factors at the beginning of the course?

RQ6 Which aspects of the perception of the learning environment explain a major portion of the variance in each outcome?

RQ7 What unique role did each of the factors in the learning environment play in mediating student outcomes?

\section{METHODOLOGY}

In this study, a validated survey covering different motivational constructs in our theoretical framework was administered to students at a large public research university in the U.S. The survey was given at the end of the semester in two semesters of traditionally taught lecturebased introductory algebra-based physics courses over the course of two years. The courses each had one recitation per week and were similar in the grading policy where students' grades mainly consisted of 2-3 midterms and 1 final exam. In general, there were little to no evidencebased active learning strategies implemented in the courses.
This course is primarily taken by junior or senior bioscience majors for whom this two-semester physics course sequence is mandatory. We analyzed the results for 854 students who completed the survey in introductory physics 1 and physics 2 classes. The University provided demographic information such as age, gender, and ethnic or racial information using an honest broker process by which the research team received the information without knowledge of the identities of the participants. From the university data, the participants were $38 \%$ male and $62 \%$ female students. We recognize that gender is fluid and not a binary construct; however, the data collected by the institution are in binary terms, so we use that in this study. Less than $1 \%$ of the students did not choose male or female and thus was not included in the study.

\section{A. Instrument validity}

The survey used in this study measured students' physics identity, self-efficacy, interest, sense of belonging, perceived recognition, and perception of interaction with peers for students enrolled in introductory algebra-based physics courses. The survey was adapted from previous research $[81,82]$ and revalidation of the motivational beliefs at our institution involved conducting one-on-one student interviews [83], exploratory factor analysis (EFA), confirmatory factor analysis (CFA), and calculation of the Pearson correlations. The survey questions for each construct and factor loadings for each question are given in Table I. 
TABLE I. Survey questions for each of the motivational constructs along with factor loadings (Lambda) from the confirmatory factor analysis for all students $(N=854)$. The rating scale for most of the self-efficacy and interest questions was NO! no yes YES! while the rating scale for the physics identity, peer interaction, and perceived recognition questions was strongly disagree, disagree, agree, strongly agree. The rating scale for the physics belonging questions was not at all true, a little true, somewhat true, mostly true, and completely true All $p$ values are $<0.001$.

\begin{tabular}{|c|c|}
\hline Construct and item & Lambda \\
\hline $\begin{array}{l}\text { Physics identity } \\
\text { I see myself as a physics person. }\end{array}$ & 1.000 \\
\hline $\begin{array}{l}\text { Physics self-efficacy } \\
\text { I am able to help my classmates with physics in the laboratory or recitation. } \\
\text { I understand concepts I have studied in physics. } \\
\text { If I study, I will do well on a physics test. } \\
\text { If I encounter a setback in a physics exam, I can overcome it. }\end{array}$ & $\begin{array}{l}0.641 \\
0.710 \\
0.734 \\
0.664\end{array}$ \\
\hline $\begin{array}{l}\text { Physics interest } \\
\text { I wonder about how physics works. } \\
\text { In general, I find physics } \\
\text { I want to know everything I can about physics. } \\
\text { I am curious about recent discoveries in physics. }\end{array}$ & $\begin{array}{l}0.696 \\
0.810 \\
0.759 \\
0.705\end{array}$ \\
\hline $\begin{array}{l}\text { Physics perceived recognition } \\
\text { My family sees me as a physics person. } \\
\text { My friends see me as a physics person. } \\
\text { My physics instructor and/or TA sees me as a physics person. }\end{array}$ & $\begin{array}{l}0.914 \\
0.914 \\
0.678\end{array}$ \\
\hline $\begin{array}{l}\text { Physics belonging } \\
\text { I feel like I belong in this class. } \\
\text { I feel like an outsider in this class. } \\
\text { I feel comfortable in this class. } \\
\text { I feel like I can be myself in this class. } \\
\text { Sometimes I worry that I do not belong in this class. }\end{array}$ & $\begin{array}{l}0.795 \\
0.676 \\
0.845 \\
0.688 \\
0.614\end{array}$ \\
\hline $\begin{array}{l}\text { Physics peer interaction } \\
\text { My experiences and interactions with other students in this class... } \\
\text { Made me feel more relaxed about learning physics. } \\
\text { Increased my confidence in my ability to do physics. } \\
\text { Increased my confidence that I can succeed in physics. } \\
\text { Increased my confidence in my ability to handle difficult physics problems. }\end{array}$ & $\begin{array}{l}0.748 \\
0.946 \\
0.942 \\
0.846\end{array}$ \\
\hline
\end{tabular}

The rating scale for this question was never, once a month, once a week, every day.

${ }^{\dagger}$ The rating scale for this question was very boring, boring, interesting, very interesting.

TABLE II. Pearson intercorrelations are given between all the predictors and outcomes.

\begin{tabular}{|c|c|c|c|c|c|c|c|c|c|c|c|c|}
\hline Observed variable & 1 & 2 & 3 & 4 & 5 & 6 & 7 & 8 & 9 & 10 & 11 & 12 \\
\hline 1. High school GPA & . & $\ldots$ & $\ldots$ & $\ldots$ & $\ldots$ & $\ldots$ & $\ldots$ & $\ldots$ & $\cdots$ & $\ldots$ & $\ldots$ & \\
\hline 2. SAT math & 0.34 & $\cdots$ & $\cdots$ & $\ldots$ & $\ldots$ & $\ldots$ & $\ldots$ & $\ldots$ & $\ldots$ & $\cdots$ & $\ldots$ & $\ldots$ \\
\hline 3. Post self-efficacy in Physics 1 & $0.11 *$ & 0.26 & $\cdots$ & $\cdots$ & $\cdots$ & $\cdots$ & $\cdots$ & $\cdots$ & $\cdots$ & $\cdots$ & $\cdots$ & \\
\hline 4. Post interest in Physics 1 & ns & ns & 0.58 & $\cdots$ & $\cdots$ & $\cdots$ & $\cdots$ & $\cdots$ & $\cdots$ & $\cdots$ & $\cdots$ & $\cdots$ \\
\hline 5. Physics 1 grade & 0.42 & 0.49 & 0.34 & $.093 *$ & $\cdots$ & $\cdots$ & $\cdots$ & $\cdots$ & $\cdots$ & $\cdots$ & $\cdots$ & $\cdots$ \\
\hline 6. Perceived recognition in Physics 2 & ns & $0.12 * *$ & 0.40 & 0.52 & 0.19 & $\ldots$ & $\ldots$ & $\ldots$ & $\ldots$ & $\ldots$ & $\ldots$ & $\ldots$ \\
\hline 7. Peer interaction in Physics 2 & ns & $0.10 *$ & 0.36 & 0.28 & $0.13 * *$ & 0.36 & $\cdots$ & $\cdots$ & $\cdots$ & $\cdots$ & $\cdots$ & $\cdots$ \\
\hline 8. Belonging in Physics 2 & 0.15 & 0.18 & 0.53 & 0.38 & 0.26 & 0.45 & 0.62 & $\cdots$ & $\cdots$ & $\cdots$ & $\cdots$ & $\cdots$ \\
\hline 9. Post self-efficacy in Physics 2 & $0.10^{*}$ & 0.22 & 0.72 & 0.46 & 0.22 & 0.58 & 0.67 & 0.79 & $\cdots$ & $\cdots$ & $\cdots$ & $\cdots$ \\
\hline 10. Post interest in Physics 2 & $0.10 * *$ & ns & 0.45 & 0.89 & ns & 0.57 & 0.39 & 0.47 & 0.60 & $\cdots$ & $\cdots$ & $\cdots$ \\
\hline 11. Physics 2 Grade & 0.36 & 0.46 & 0.25 & ns & 0.68 & 0.22 & 0.21 & 0.35 & 0.32 & $0.10 * *$ & $\cdots$ & $\cdots$ \\
\hline 12. Physics identity in Physics 2 & ns & 0.13 & 0.46 & 0.52 & 0.17 & 0.82 & 0.37 & 0.45 & 0.20 & 0.57 & 0.20 & \\
\hline
\end{tabular}

$*=p<0.05, * *=p<0.01$, no superscript $*=p<0.001$, ns $=$ nonsignificant. 
The pairwise Pearson correlations are given in Table II. Pearson's $r$ values signify the strength of the pairwise correlations between constructs. The intercorrelations vary in strength, but none of the correlations are so high that the constructs cannot be separately examined. The only high inter-correlations were between post interest in physics 1 and post interest in physics $2(0.89)$ and between physics identity in physics 2 and perceived recognition in physics 2 $(0.82)$. Prior study shows that there is a high correlation in interest from the beginning to the end of the physics courses and from physics 1 and physics 2 in calculusbased introductory physics courses [83]. Additionally, perceived recognition is associated with external identity whereas physics identity asks about internal identity so there tends to be a high correlation between the constructs. Both correlations are low enough that they can be considered separate constructs.

The physics identity question evaluated whether the students see themselves as a physics person [84]. The physics self-efficacy questions measured students' confidence in their ability to understand physics and solve problems [81,84-86]. The interest in physics questions measured students' enthusiasm and curiosity to learn physics and ideas related to physics [85]. The sense of belonging questions on the survey measured whether students felt like they belonged in the introductory physics classroom or not $[77,82]$. The perceived recognition questions measured the extent to which students thought that other people see them as a physics person [84]. Lastly, the perception of peer interaction questions (which we will refer to as peer interaction for brevity) measured whether students thought that working with their peers is beneficial for their confidence to do physics $[87,88]$.

The questions in the study were designed on a Likert scale of 1 (low endorsement) to 4 (high endorsement) except for the sense of belonging questions which were designed on a scale of 1 to 5 [89]. A lower score was indicative of a negative endorsement of the survey construct while a higher score was related to a positive belief of the construct. Some of the questions were reverse coded (e.g., I feel like an outsider in this class).

\section{B. Analysis}

Initially, we analyzed the descriptive statistics and compared female and male students' mean scores on the predictors and outcomes for statistical significance using $t$ tests and to investigate the effect size using Cohen's $d$ [90]. Cohen's $d$ is $d=\left(\mu_{m}-\mu_{f}\right) / \sigma_{\text {pooled }}$, where $\mu_{m}$ is the average score of male students, $\mu_{f}$ is the average score of female students, and $\sigma_{\text {pooled }}$ is the pooled standard deviation (or weighted standard deviation for men and women) for all students. To quantify the statistical significance and relative strength of our frameworks' path links, we used structural equation modeling as a statistical tool by using $\mathrm{R}$ (lavaan package) with a maximum likelihood estimation method [91]. SEM is an extension of multiple regression and allows one to conduct several multiple regressions simultaneously between variables in one estimation model. This is an improvement over multiple regression since it allows us to calculate the overall goodness of fit and allows for all estimates to be standardized simultaneously so there can be direct comparisons between different structural components. SEM also has an option to handle missing data using the full estimation maximum likelihood "ML" estimation feature, which improves power since it imputes missing data so students only missing some data are not dropped. We report model fit for SEM by using the comparative fit index (CFI), Tucker-Lewis index (TLI), root mean square error of approximation (RMSEA), and standardized root mean square residuals (SRMR). Commonly used thresholds for goodness of fit are as follows: CFI and TLI $>0.90$, and SRMR and RMSEA $<0.08$ [92].

The model estimates were performed using gender moderation analysis to check whether any of the relations between variables show differences across gender by using "lavaan" to conduct multigroup SEM [93]. In moderation analysis, the predictive relationship (regression path) between two variables is tested for two or more different groups (e.g., men and women) simultaneously. If the predictive relationship is different for the groups (i.e., the values of the regression coefficients are not the same for the correlation between the two constructs for different groups), then there is a moderation effect in the model. For example, in a study focusing on how smoking predicts lung cancer, if there was a moderation by gender, the predictive relation (regression coefficient) between smoking and lung cancer would be different for women and men. However, if the regression coefficients for how smoking predicts lung cancer were exactly the same for women and men, then there is no moderation by gender and one can just focus on mediation analysis by gender. Initially, we tested different levels of measurement invariance model. In each step, we fixed different elements of the model to equality across gender and compared the results to the previous step using the likelihood ratio test [93]. Since we did not find any statistically significant moderation by gender, we tested the theoretical model in a mediation analysis, using gender as a variable directly predicting items to examine the resulting structural paths between constructs (in the mediation analysis, if there are paths from gender to any of the constructs as we found in our results discussed in the next section, it implies that women and men did not have the same average value for those constructs even though the regression coefficients between the constructs are the same for women and men). We made various models with different learning environment factors to investigate the effects of the various factors on the student outcomes as shown in Fig. 1. 


\section{RESULTS AND DISCUSSION}

\section{A. Gender differences in predictors and outcomes}

Women had statistically significantly lower mean values in the majority of the predictors and outcomes than men, except for High School GPA, which favors women (see Table III). There was also no statistically significant difference in the mean of the physics 2 grade between men (3.14) and women (3.05). The gender differences in motivational outcomes in physics 2 despite women having no statistically significant grade difference is a cause for concern since student motivational outcomes can impact their future career trajectories. Therefore, it is important to improve the physics learning environments to make them equitable and inclusive so that these gaps in motivational outcomes can be eliminated.

\section{B. SEM path model}

We used SEM to investigate the relationships between the constructs and to unpack each construct's contribution to explaining the self-efficacy, interest, and physics identity of women and men at the end of physics 2 . We initially conducted gender moderation analysis between variables using multigroup SEM to investigate if any of the predictive relationships between the motivational constructs were different across gender. There were no group differences at the levels of weak and strong measurement invariance and at the level of regression coefficients. Thus, there is no moderation effect by gender. Therefore, we proceeded to gender mediation analysis. In particular, we proceeded to gender mediation analysis to understand the extent to which gender differences in students' outcomes at the end of the introductory physics sequence (self-efficacy, interest, grade, and physics identity) were mediated by differences in students' initial self-efficacy, interest, prior knowledge in physics, pre-college academic measures
(High School GPA and SAT math) and the perception of the physics learning environment.

\section{Model 1: Perceived recognition}

In our first model, the only learning environment factor included was perceived recognition (we keep this factor because it has been previously found to be a predictor of physics identity in the theoretical framework we adapted). The result of the SEM path model is presented visually in Fig. 2. The model fit indices indicate a good fit to the data: $\mathrm{CFI}=0.931(>0.90), \mathrm{TLI}=0.919(>0.90)$, RMSEA $=$ $0.052(<0.08)$, and SRMR $=0.044(<0.08)$. Interestingly, we found that the only direct connections to gender involved the high school factors, SAT math $(\beta=0.15)$ and H.S. GPA $(\beta=-0.11)$, as well as self-efficacy in physics $1(\beta=0.22)$ and interest (0.37) at the end of physics 1. For example, gender directly mediates SAT math and self-efficacy in physics 1 favoring men but the regression coefficient showing the predictive relation between SAT math and selfefficacy in physics 1 is 0.24 for both women and men (if this regression coefficient was not the same for women and men, we would not have been able to do mediation analysis by gender since in that case, gender would have moderated the relation between these two constructs). We note that gender has indirect effects on physics 1 grade, perceived recognition, and the outcome variables (physics 2 grade, self-efficacy, interest, and identity).

Thus, in this model shown in Fig. 2, self-efficacy, interest and perceived recognition in physics 2 had a direct effect on physics identity, and there were no direct effects from gender, grade in physics 2, or any of the pre-college and physics 1 variables. Students' perceived recognition in physics 2 had the largest direct effect (regression coefficient $\beta=0.69$ ) while self-efficacy $(\beta=0.13)$ and interest $(\beta=0.10)$ had similar, smaller direct effects on the physics identity.

Self-efficacy in physics 2 is largely predicted by selfefficacy in physics $1(\beta=0.60)$ and perceived recognition

TABLE III. Mean predictor and outcome values by gender as well as statistical significance ( $p$ values) and effect sizes (Cohen's $d$ ) by gender.

\begin{tabular}{lccrr}
\hline \hline & \multicolumn{3}{c}{ Mean } & \\
\cline { 2 - 4 } Predictors and outcomes (score range) & Male & Female & $p$ value & Cohen's $d$ \\
\hline High school GPA (0-5) & 4.05 & 4.14 & 0.003 & -0.22 \\
SAT math (200-800) & 682 & 660 & $<0.001$ & 0.32 \\
Post Self-efficacy in physics 1 (1-4) & 2.98 & 2.73 & $<0.001$ & 0.49 \\
Post Interest in physics 1 (1-4) & 2.81 & 2.38 & $<0.001$ & 0.71 \\
Physics 1 grade (0-4) & 3.39 & 3.23 & 0.003 & 0.40 \\
Perceived recognition in physics 2 (1-4) & 2.24 & 1.98 & $<0.001$ & 0.39 \\
Peer Interaction in physics 2 (1-4) & 2.94 & 2.79 & 0.001 & 0.24 \\
Belonging in physics 2 (1-5) & 3.69 & 3.45 & $<0.001$ & 0.28 \\
Post self-efficacy in physics 2 (1-4) & 2.94 & 2.73 & $<0.001$ & 0.40 \\
Post Interest in physics 2 (1-4) & 2.77 & 2.32 & $<0.001$ & 0.73 \\
Physics 2 grade (0-4) & 3.14 & 3.05 & 0.104 & 0.12 \\
Physics identity in physics 2 (1-4) & 2.19 & 1.85 & $<0.001$ & 0.45 \\
\hline \hline
\end{tabular}




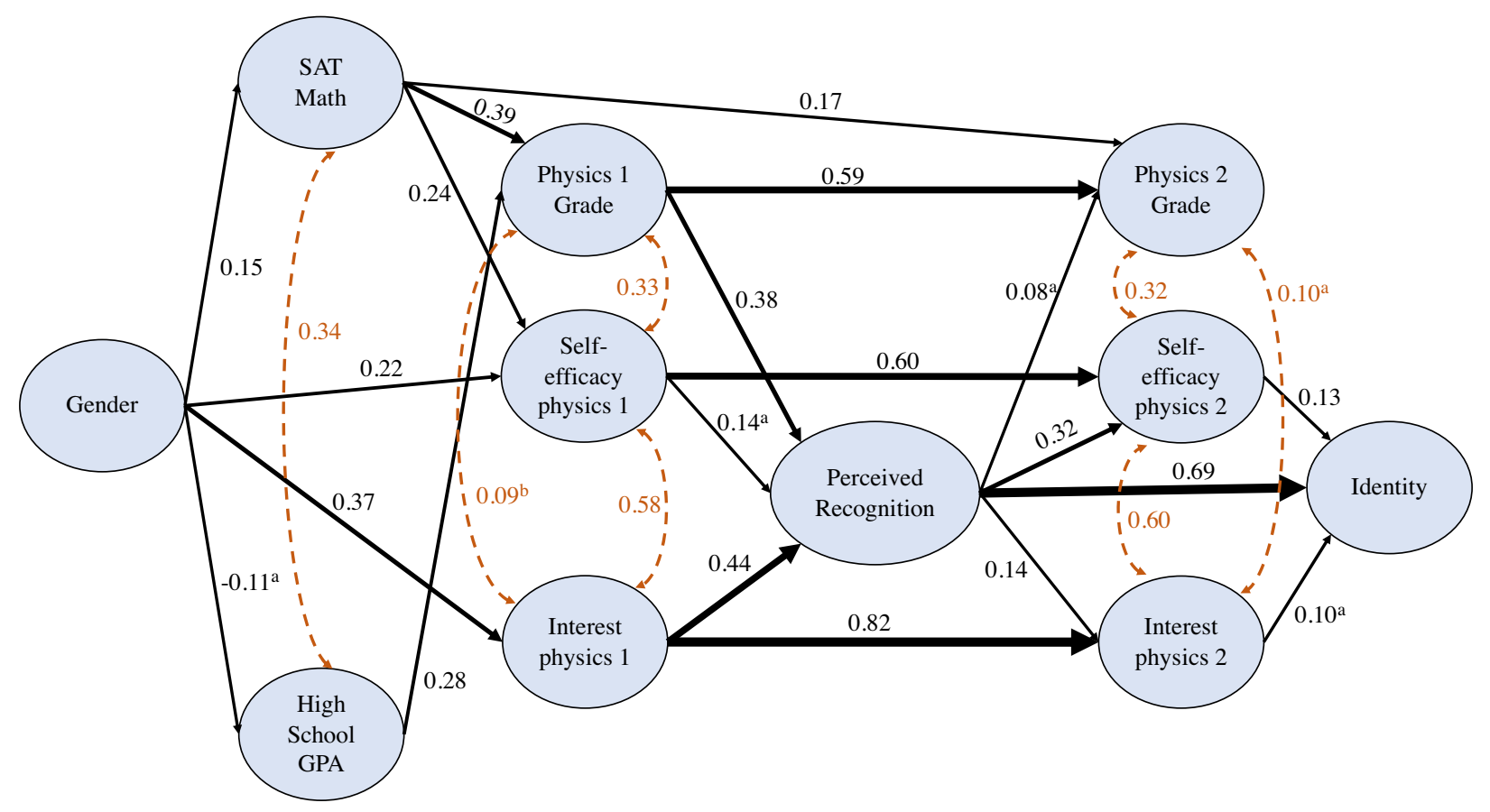

FIG. 2. Result of the path analysis part of the SEM showing mediation between gender and outcomes in physics through various mediating factors for model 1 . Perceived recognition is the only motivational construct in the learning environment. The line thickness is the relative magnitude of the regression coefficients $\beta$. The dashed lines indicate covariances between constructs. All $p$ values are indicated by no superscript for $p<0.001$, superscript "a" for $p<0.01$, and superscript "b" for $p<0.05$.

$(\beta=0.32)$. Similarly, interest in physics 2 , has direct effects from interest in physics 1 and perceived recognition with interest in physics 1 has the largest direct effect $(\beta=0.82)$, and perceived recognition has a smaller direct effect $(\beta=0.14)$. The students' grade in physics 2 has the largest direct effect from their grade in physics 1 $(\beta=0.59)$, and small direct effects from their SAT math scores $(\beta=0.17)$ and perceived recognition $(\beta=0.08)$. Perceived recognition plays an important role in predicting student motivational outcomes and therefore instructors must find different ways to positively recognize students in their classroom.

\section{Model 2: Perceived recognition and peer interaction}

In our second model, we added perception of peer interaction into the learning environment of physics 2 . The result of the SEM is presented visually in Fig. 3. The model fit indices indicate an even better fit to the data than the first model: $\quad \mathrm{CFI}=0.943 \quad(>0.90), \quad \mathrm{TLI}=0.934$ $(>0.90)$, RMSEA $=0.048(<0.08)$, and $\mathrm{SRMR}=0.045$ $(<0.08)$. There are minimal differences in the direct effect of gender to the other factors in the model. Additionally, identity has the same direct paths and $\beta$ values as in model 1. However, there are differences in the outcomes of grade, self-efficacy, and interest in physics 2 . The direct path from perceived recognition to grade is not present in this model and instead is replaced with a direct path from peer interaction $(\beta=0.11)$. The direct paths from perceived recognition and interest in physics 1 to interest in physics 2 are slightly smaller compared to model 1 and there is a new direct path from peer interaction $(\beta=0.16)$. The largest change is in the direct paths to self-efficacy in physics 2 . The direct paths from self-efficacy in physics 1 and perceived recognition decrease by approximately a $\beta$ value of 0.10 (from 0.60 to 0.50 and from 0.32 to 0.21 , respectively). Additionally, a direct path from peer interaction to self-efficacy in physics 2 is significant in this model $(\beta=0.40)$. Therefore, students' perception of their peer interaction plays a significant role in predicting their learning and motivational outcomes. Thus, it may be beneficial for instructors to influence peer interaction by introducing more active learning pedagogy in their classroom in an equitable and inclusive learning environment (e.g., ensuring that men do not dominate and ignore or marginalize women during peer interaction).

\section{E. Model 3: Perceived recognition and belonging}

In our third model, the learning environment consisted of perceived recognition and belonging in physics 2 . The result of the SEM is presented visually in Fig. 4. The model fit indices indicate a comparable fit to the data as the first model: $\mathrm{CFI}=0.931 \quad(>0.90), \quad \mathrm{TLI}=0.922(0.90)$, RMSEA $=$ $0.049(<0.08)$, and SRMR $=0.045(<0.08)$. There are minimal differences in the direct effect of gender to various factors. The same direct paths and $\beta$ values to identity from the first two models are present. However, there are some 


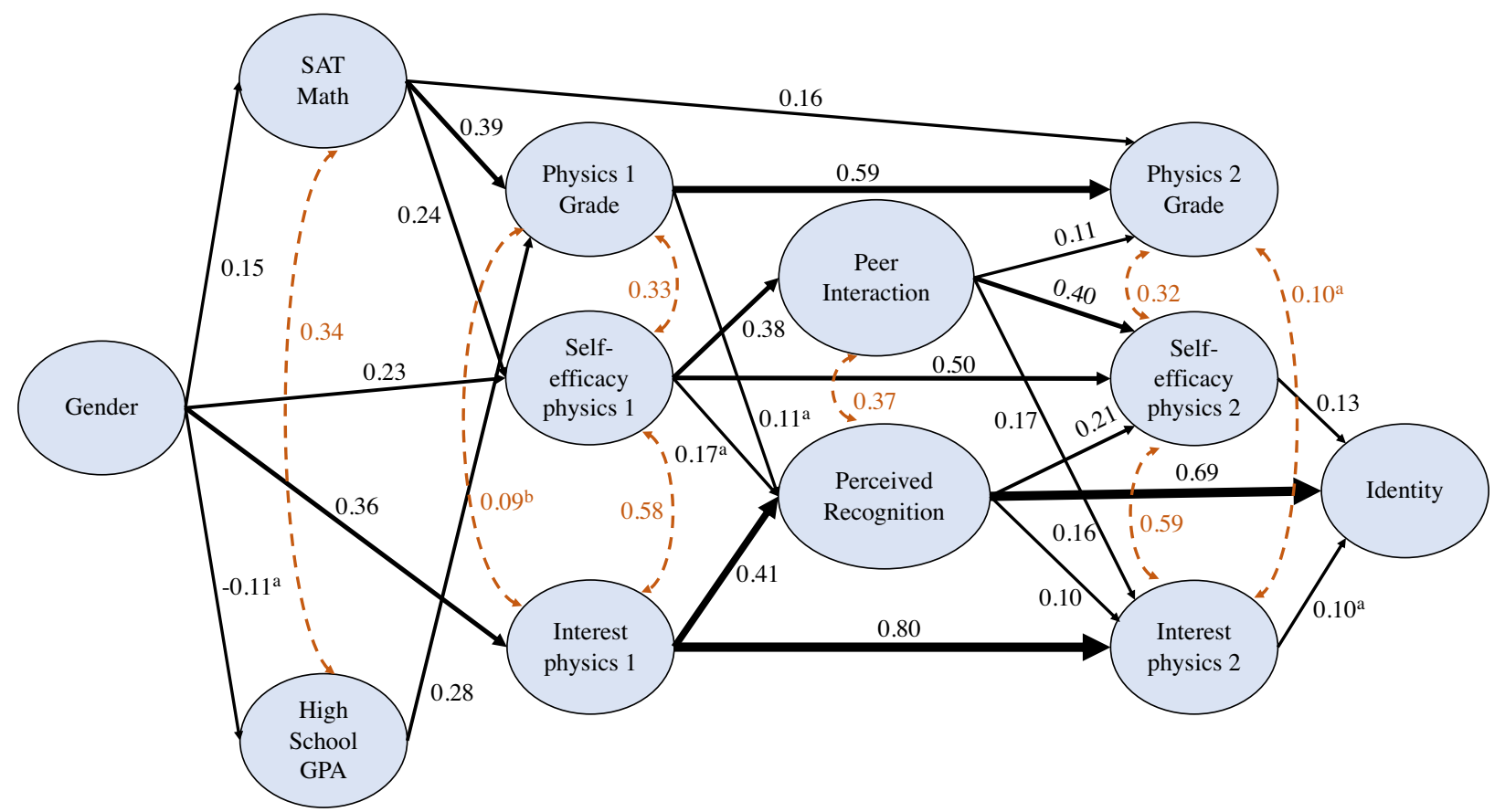

FIG. 3. Result of the path analysis of the SEM between gender and outcomes in physics through various mediating factors for model 2. Perceived recognition and peer interaction are the two factors included in the learning environment. The line thickness is the relative magnitude of $\beta$ values. The dashed lines indicate covariances between constructs. All $p$ values are indicated by no superscript for $p<0.001$, superscript "a" for $p<0.01$, and superscript "b" for $p<0.05$.

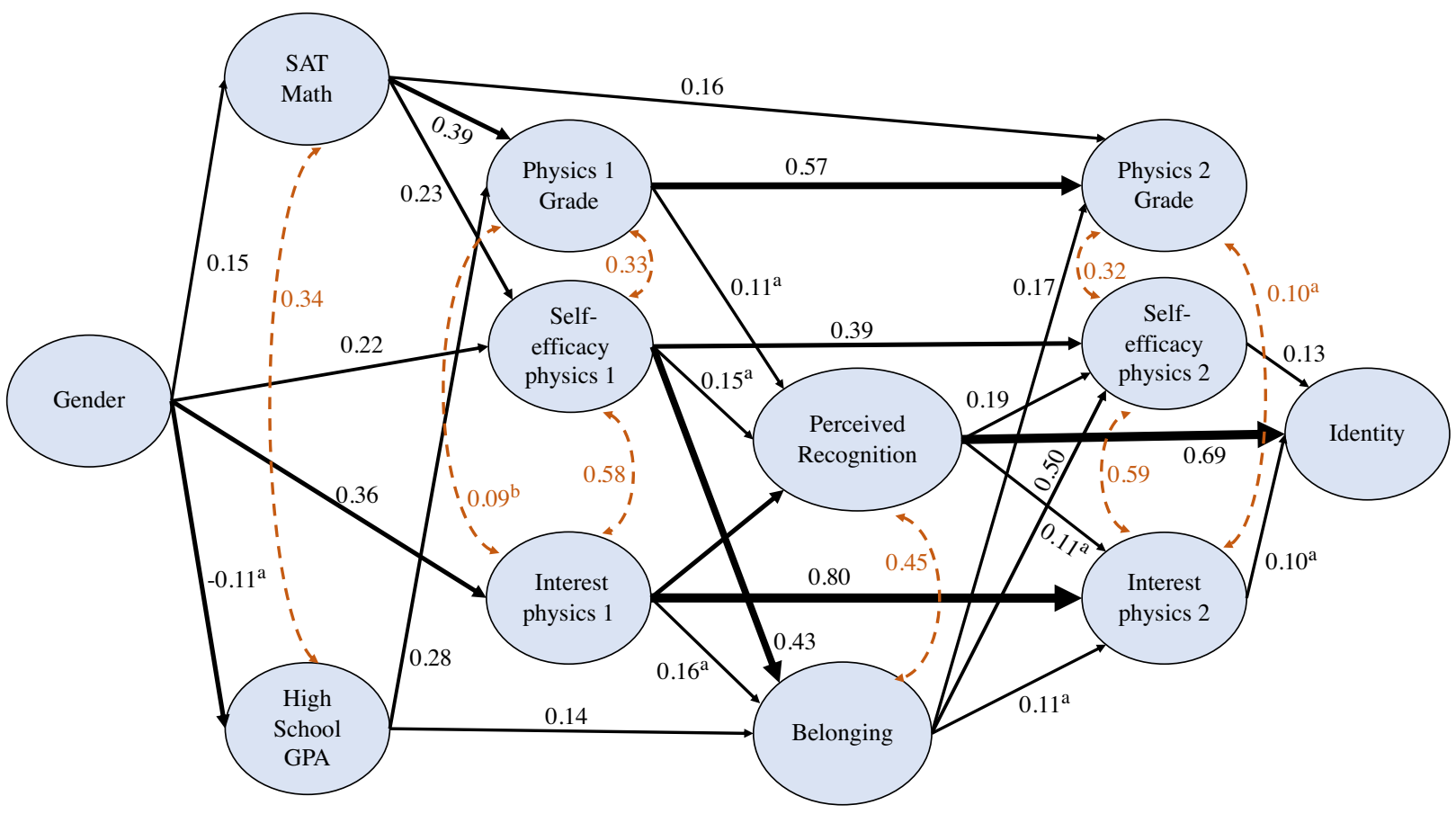

FIG. 4. Result of the path analysis part of SEM between gender and outcomes in physics through various mediating factors for model 3. Perceived recognition and belonging are factors in the learning environment. The line thickness is the relative magnitude of $\beta$ values. The dashed lines indicate covariances between constructs. All $p$ values are indicated by no superscript for $p<0.001$, superscript "a" for $p<0.01$, and superscript " $\mathrm{b}$ " for $p<0.05$. 




FIG. 5. Result of the path analysis part of the SEM between gender and outcomes in physics through various mediating factors for model 4. Perceived recognition, peer interaction, and belonging are the motivational constructs included in the learning environment. The line thickness indicates the relative magnitude of $\beta$ values. The dashed lines indicate covariances between constructs. All $p$ values are indicated by no superscript for $p<0.001$, superscript "a" for $p<0.01$, and superscript "b" for $p<0.05$.

differences in the outcomes of grade, self-efficacy, and interest in physics 2 . The only direct path to physics 2 grade from the learning environment factors is from belonging $(\beta=0.17)$. Similar to the model with peer interaction and perceived recognition, the path between perceived recognition and self-efficacy was reduced and a direct path from belonging to self-efficacy is present in this model $(\beta=0.50)$. Since belonging is important for students' outcomes in the course, it is crucial that instructors increase students' sense of belonging. For example, instructors could ensure that students' ideas are respected by others in the class and students recognize that everyone struggles while learning physics and struggling is the stepping stone to learning physics.

\section{F. Model 4: Perceived recognition, peer interaction, and belonging}

Our fourth and final model included all three perceptions of the physics learning environment factors; belonging, peer interaction, and perceived recognition in physics 2 . The result of the SEM is presented visually in Fig. 5. The model fit indices indicate a good fit to the data: $\mathrm{CFI}=$ $0.936(>0.90)$, TLI $=0.927(>0.90)$, RMSEA $=0.047$ $(<0.08)$, and SRMR $=0.046(<0.08)$. One difference in this model from the second model is that the direct path from peer interaction to physics 2 grade does not appear and instead there is a direct path from belonging to physics 2 grade $(\beta=0.17)$. Self-efficacy has a direct path from belonging ( $\beta=0.34$ ). The direct paths to self-efficacy from peer interaction and perceived recognition are reduced (from 0.40 to 0.26 and from 0.21 to 0.17 , respectively). The direct paths to identity from perceived recognition, self-efficacy, and interest in physics 2 remain unchanged in all four models. Thus, all three learning environment factors (perceived recognition, peer interaction, and belonging) predict student outcomes in the physics 2 course.

\section{G. Direct and indirect paths}

Since not all of the factors directly relate to student outcomes, we found the direct and indirect paths of all the control variables and learning environment factors to the student outcomes in model 4 . An indirect path is measured by finding the product of each path $(\beta)$ from a given variable to an outcome variable. The total indirect path for a given variable and outcome was found by adding all of the indirect paths together. For example, there are two indirect paths from peer interaction to identity. The first path goes from peer interaction $\rightarrow$ S.E. physics $2 \rightarrow$ identity $(0.26 * 0.13=0.03)$. The second path goes from peer interaction $\rightarrow$ interest physics $2 \rightarrow$ identity $(0.16 * 0.10=0.02)$. So, the total indirect path from peer interaction to identity is $0.03+0.02=0.05$. The total path was calculated by adding the direct path and total indirect path together. A summary of all direct and indirect paths can be found in Table IV. 
TABLE IV. Regression coefficients for direct paths and indirect paths from the controlled variables and learning environment factors to every student outcome in model 4.

\begin{tabular}{|c|c|c|c|c|}
\hline Outcome & Predictor & Direct Path & Total indirect path & Total path \\
\hline \multirow[t]{8}{*}{ Grade physics 2} & SAT math & 0.16 & 0.24 & 0.40 \\
\hline & High school GPA & 0.00 & 0.18 & 0.18 \\
\hline & Grade physics 1 & 0.56 & 0.00 & 0.56 \\
\hline & Self-efficacy physics 1 & 0.00 & 0.10 & 0.10 \\
\hline & Interest physics 1 & 0.00 & 0.00 & 0.00 \\
\hline & Peer interaction & 0.00 & 0.00 & 0.00 \\
\hline & Perceived recognition & 0.00 & 0.00 & 0.00 \\
\hline & Belonging & 0.17 & 0.00 & 0.17 \\
\hline \multirow[t]{8}{*}{ Self-efficacy physics 2} & SAT math & 0.00 & 0.17 & 0.17 \\
\hline & High school GPA & 0.00 & 0.04 & 0.04 \\
\hline & Grade physics 1 & 0.00 & 0.02 & 0.02 \\
\hline & Self-efficacy physics 1 & 0.38 & 0.32 & 0.70 \\
\hline & Interest physics 1 & 0.00 & 0.06 & 0.06 \\
\hline & Peer Interaction & 0.26 & 0.00 & 0.26 \\
\hline & Perceived recognition & 0.17 & 0.00 & 0.17 \\
\hline & Belonging & 0.34 & 0.00 & 0.34 \\
\hline \multirow[t]{8}{*}{ Interest physics 2} & SAT math & 0.00 & 0.02 & 0.02 \\
\hline & High School GPA & 0.00 & 0.00 & 0.00 \\
\hline & Grade physics 1 & 0.00 & 0.01 & 0.01 \\
\hline & Self-efficacy physics 1 & 0.00 & 0.08 & 0.08 \\
\hline & Interest physics 1 & 0.80 & 0.04 & 0.84 \\
\hline & Peer interaction & 0.16 & 0.00 & 0.16 \\
\hline & Perceived recognition & 0.11 & 0.00 & 0.11 \\
\hline & Belonging & 0.00 & 0.00 & 0.00 \\
\hline \multirow[t]{8}{*}{ Identity } & SAT math & 0.00 & 0.07 & 0.07 \\
\hline & High school GPA & 0.00 & 0.03 & 0.03 \\
\hline & Grade physics 1 & 0.00 & 0.07 & 0.07 \\
\hline & Self-efficacy physics 1 & 0.00 & 0.23 & 0.23 \\
\hline & Interest physics 1 & 0.00 & 0.35 & 0.35 \\
\hline & Peer interaction & 0.00 & 0.05 & 0.05 \\
\hline & Perceived recognition & 0.69 & 0.03 & 0.72 \\
\hline & Belonging & 0.00 & 0.04 & 0.04 \\
\hline
\end{tabular}

TABLE V. Adjusted coefficients of determination (adjusted $\mathrm{R}^{2}$ ) for all variables in the four different models on the impact of the learning environment. P.R. is perceived recognition, Peer is peer interaction, and Bel is belonging.

\begin{tabular}{lcccc}
\hline \hline & \multicolumn{3}{c}{ Adjusted R } \\
\cline { 2 - 5 } & Model 1 & Model 2 & Model 3 & Model 4 \\
\cline { 2 - 5 } Variable & P.R. & P.R. + Peer & P.R. + Bel & P.R. + Peer + Bel \\
\hline High school GPA & 0.00 & 0.00 & 0.00 & 0.00 \\
SAT math & 0.01 & 0.01 & 0.01 & 0.01 \\
Post self-efficacy in physics 1 & 0.11 & 0.11 & 0.11 & 0.11 \\
Post interest in physics 1 & 0.12 & 0.12 & 0.12 & 0.12 \\
Physics 1 Grade & 0.30 & 0.30 & 0.30 & 0.30 \\
Perceived recognition in Physics & 0.29 & 0.29 & 0.29 & 0.28 \\
Peer interaction in physics 2 & $\ldots$ & 0.13 & $\ldots .13$ \\
Belonging in physics 2 & $\ldots$ & $\ldots$ & 0.30 & 0.32 \\
Post self-efficacy in physics 2 & 0.61 & 0.75 & 0.78 & 0.81 \\
Post interest in physics 2 & 0.82 & 0.82 & 0.82 & 0.82 \\
Physics 2 Grade & 0.49 & 0.49 & 0.50 & 0.50 \\
Physics identity in physics 2 & 0.69 & 0.69 & 0.69 & 0.69 \\
\hline \hline
\end{tabular}

\footnotetext{
*all $p$ values are $<0.001$.
} 


\section{H. Variance explained by each model}

After constructing the models with each additional learning environment factor, we calculated the coefficient of determination (adjusted $R^{2}$ ) of each construct in every model to investigate the proportion of variance explained by each model (Table V). We found that each model explained the same amount of variance for physics interest, grade, and identity in physics 2 . This means that adding in peer interaction and belonging did not explain any more variance in those three outcome variables. However, the variance in self-efficacy for physics 2 increased for each consecutive model. Model 1 explained $61 \%$ of the variance in self-efficacy, model 2 explained $75 \%$ of the variance, model 3 explained $78 \%$, and model 4 explained $81 \%$ of the variance. Therefore, all three of the learning environment factors play a crucial role in predicting student outcomes (and particularly self-efficacy) in the course. Thus, it is important that instructors consider all three learning environment factors to create a more equitable and inclusive environment so all students can succeed.

\section{SUMMARY AND IMPLICATIONS}

Women taking traditionally taught algebra-based physics courses have lower motivational beliefs than men at the end of physics 2, a pattern similar to what we observed in the calculus-based physics courses [67,71], despite the higher representation of women in the former- $62 \%$ of students versus 30\%, respectively. In response to RQ1, we find that at the end of physics 2, women had lower self-efficacy, interest, perceived recognition, peer interaction, belonging, and physics identity (Table III). Women and men did not have statistically significant differences in course grade at the end of physics 2 , but women had statistically significantly lower grades than men in physics 1 (Table III). One hypothesis for gender difference in grades in physics 1 (but not in physics 2) is that the high school physics course that many students take overlaps with the content of physics 1 (mechanics) and male students might benefit more from the way those high school courses are taught and their greater familiarity with this content may provide them an advantage in college physics 1 particularly if college instructors do not make an effort to create an equitable and inclusive learning environment and level the playing field. However, what is also a cause for concern is that women had lower motivational beliefs in both courses than men. Also, women had lower self-efficacy coming into the physics 2 course, which we hypothesize to be due to societal stereotypes about who can excel in physics and previous gendered experiences women had before they came into the class. The learning environment in physics 2 did not alleviate these gender differences. Since students' selfefficacy has important implications for student performance in the course and can also impact their career trajectories, it is important to make physics learning environments equitable and inclusive so that the gap can be eliminated. This entails creating a learning environment in which women feel recognized by their instructors and have a high sense of belonging in the course since these beliefs are important for excelling in the course and play a key role in predicting physics identity, interest, and self-efficacy.

In response to $\mathbf{R Q 2}$, we did not find moderation by gender for any regression path in our models. Therefore, SEM mediation models were implemented to help answer RQ3. We find that gender mediates certain factors we controlled for, such as the high school GPA, SAT math scores, interest, and self-efficacy at the end of physics 1 . However, gender did not directly predict any learning environment or student outcome factors. This was true for all of our models and further supports the finding that women begin and end physics 2 with lower motivational beliefs than men. This is potentially due to societal stereotypes and biases women experience about who belongs in physics and can excel in physics throughout their life and persist if instructors do not create an equitable and inclusive learning environment. Thus, instructors must be provided incentives and support to make physics learning environments equitable and inclusive in order to eliminate these differences.

To answer question RQ4, in all four models perceived recognition, interest, and self-efficacy at the end of physics 2 directly influenced identity. Perceived recognition had the most influence on identity $(\beta=0.69)$ followed by selfefficacy $(\beta=0.13)$ and interest $(\beta=0.10)$. This is consistent with past studies [67]. Indirect effects on identity include belonging and peer interaction, as seen in Table IV. However, there was no direct path from students' grades to their physics identity so that how well students did in the course did not predict whether they felt like a physics person. Since students' physics identity may have important implications for their future career choices, it is important to improve all students' physics identity in these introductory physics courses.

Turning to the learning environment factors, we focus on responses to RQ5 and RQ6. The factors that predicted selfefficacy in both physics 1 and 2 were perceived recognition $(\beta=0.17)$, peer interaction $(\beta=0.26)$, and belonging $(\beta=0.34)$. Interest in physics 2 was predicted by the learning environment factors of perceived recognition $(\beta=0.11)$ and peer interaction $(\beta=0.16)$ as well as interest in physics $1(\beta=0.80)$. Unlike self-efficacy, which was predicted by all learning environment factors, interest at the end of the physics 2 course was primarily predicted by interest at the end of physics 1 . Despite this finding in traditionally taught courses, interest in physics has the potential to show desired change at the end of the course if instructors explicitly focus on this goal. One possible way to influence students' interest is to engage them with problems that relate to their prospective majors or occupations or that are of interest to them in general. The only learning environment factor that predicted physics 2 grade in the fourth and final model was belonging $(\beta=0.17)$. In 
addition, physics 1 grade and SAT math also affected this outcome. While the only direct path to grade in the final model was students' sense of belonging, perceived recognition and peer interaction may still predict physics 2 grade through some of the shared variances in these factors. As we observed in models 1 and 2, peer interaction and perceived recognition had direct paths to physics 2 grade when belonging was not included as a learning environment factor. From these results, it is clear that the learning environment is important when predicting student outcomes. Therefore, physics instructors should embrace their role in improving student outcomes in their courses and create an equitable and inclusive learning environment in which all students thrive.

In response to $\mathbf{R Q 7}$, Table $V$ shows the unique role each of the learning environment factors plays in mediating student outcomes. The variance explained in interest, grade, and identity in physics 2 do not change significantly when more learning environment factors are added. For interest, this is because most of the variance in all models is explained by interest in physics 1 instead of the learning environment factors. For grade in physics 2 , this is because most of the learning environment influence comes from the shared variance between the learning environment factors. When only perceived recognition is included in the model, it directly influences physics 2 grade; when perceived recognition and peer interaction are included in the model, peer interaction directly influences physics 2 grade; and in the final model, only belonging influences physics 2 grade. It is important to note that only about $50 \%$ of the variance is explained for the physics 2 grade, so there are still other factors that predict grade that are not included in the model. Perceived recognition plays a large role in predicting identity and was included in each of our models. Unlike other outcomes, self-efficacy had more variance explained when more learning environment factors were added. In particular, peer interaction played an important role in predicting selfefficacy and it explained 14\% more of the variance when included in the model. When belonging is also added to the model, it explains an additional $6 \%$ of the variance. Thus, it is important to include all three learning environment factors in the model to help explain the student outcomes. While each factor plays a unique role in explaining student outcomes, sense of belonging, peer interaction, and perceived recognition can influence each other to create better outcomes in equitable and inclusive learning environments [94]. Not only can the learning environment factors influence each other, but as seen from Table II, self-efficacy and grade, selfefficacy and interest, as well as self-efficacy and perceived recognition are all correlated with each other.

Instructors could potentially change student outcomes for the better if they can provide support for factors they can control (i.e., learning environment factors). It is important to note that the physics 1 and physics 2 courses in this study were traditionally taught lecture-based physics courses where student grades heavily depended on two or three midterms and a final exam. There were little to no researchbased active engagement strategies used in the classroom. Instructors can influence students' peer interaction with each other by providing time for students to work in groups during class or recitations and making sure that all student voices are heard equally while discussing problems. This could in turn help increase students' sense of belonging in the classroom if they observe that their ideas are respected by other students in the classroom. In addition, by not letting men dominate the conversations in class and explicitly praising effort and affirming women when they do well or make progress in the class, the gender gap in students' perceived recognition could potentially be decreased. This is especially important when implementing active learning pedagogy in the classroom. If not implemented using teaching strategies that are equitable and inclusive, men have been shown to not only dominate responding to questions in class but also while working in groups which can lower women's self-efficacy [95]. Moreover, instructors should be careful not to say that problems are "trivial," "easy," or "obvious" when students ask them for help after trying their best because otherwise female students are more likely to feel disparaged (or negatively recognized). What instructors need to realize is that what is important is the impact they are having on the students and not their intentions. Brief social-psychological classroom interventions, or mindset or sense of belonging interventions, have also been shown to eliminate or reduce the gender gap in performance $[7,8,96,97]$. It would also help if instructors make it clear to students that they have high expectations of them, but they know that they have what it takes to meet those expectations and excelling in physics entails working hard and working smart and using effective approaches to learning and getting help from instructors and peers frequently as needed.

In summary, instructors and TAs need to create a learning environment that emphasizes recognizing their students, allowing for positive peer interactions, and providing a space where all students can feel like they belong in physics. From our analysis, these factors play important roles in predicting students' grade, self-efficacy, interest, and identity in physics. We hypothesize that many of these differences are due to the stereotypes and past experiences women have that perpetuate through to the end of these introductory physics courses even though women are not underrepresented in them. It is important to note that the learning environment includes not only what happens in the classroom. Student interactions with each other while they are doing homework, students' experiences in an instructor or TA's office hours, interactions between students and the instructor over email, and other circumstances all contribute to the students' learning environment. All of those interactions can affect students' identity, self-efficacy, and interest in physics by the end of the semester. 


\section{ACKNOWLEDGMENTS}

This work was supported by Grant No. NSF DUE-152457. APC charges for this article were partially paid by the University Library System, University of Pittsburgh. We thank all students who participated in this research and Dr. Robert Devaty for his constructive feedback on this manuscript.

[1] Science \& Engineering Degree Attainment: 2004-2014 (NSC Research Center, Herndon, VA, 2015) https:// nscresearchcenter.org/snapshotreport-degreeattainment15/.

[2] Percent of Physics Bachelors and PhDs Earned by Women, Classes of 1975 through 2016 (AIP Publishing, New York, 2016), https://www.aip.org/statistics/data-graphics/percentphysics-bachelors-and-phds-earned-women-classes-1975through-2016.

[3] S. G. Brainard and L. Carlin, A six-year longitudinal study of undergraduate women in engineering and science, J. Eng. Educ. 87, 369 (1998).

[4] E. Seymour, Tracking the processes of change in US undergraduate education in science, mathematics, engineering, and technology, Sci. Educ. 86, 79 (2002).

[5] A. Miyake, L. E. Kost-Smith, N. D. Finkelstein, S. J. Pollock, G. L. Cohen, and T. A. Ito, Reducing the gender achievement gap in college science: A classroom study of values affirmation, Science 330, 1234 (2010).

[6] B. L. Whitten, S. Foster, and M. Duncombe, What works for women in undergraduate physics?, Phys. Today $\mathbf{5 6}, 46$ (2003).

[7] G. M. Walton, C. Logel, J. M. Peach, S. J. Spencer, and M. P. Zanna, Two brief interventions to mitigate a "chilly climate" transform women's experience, relationships, and achievement in engineering, J. Educ. Psychol. 107, 468 (2015).

[8] J. M. Harackiewicz, E. A. Canning, Y. Tibbetts, S. J. Priniski, and J. S. Hyde, Closing achievement gaps with a utility-value intervention: Disentangling race and social class, J. Pers. Soc. Psychol. 111, 745 (2016).

[9] L. Tsui, Effective strategies to increase diversity in STEM fields: A review of the research literature, J. Negro Educ. 76, 555 (2007).

[10] L. E. Kost-Smith, S. J. Pollock, and N. D. Finkelstein, Gender disparities in second-semester college physics: The incremental effects of a "smog of bias", Phys. Rev. Phys. Educ. Res. 6, 020112 (2010).

[11] P. Vincent-Ruz, K. Binning, C.D. Schunn, and J. Grabowski, The effect of math SAT on women's chemistry competency beliefs, Chem. Educ. Res. Pract. 19, 342 (2018).

[12] E. Seymour, N. M. Hewitt, and C. M. Friend, Talking About Leaving: Why Undergraduates Leave the Sciences (Westview Press, Boulder, CO, 1997), Vol. 12.

[13] J. Blue, A. L. Traxler, and X. C. Cid, Gender matters, Phys. Today 71, 40 (2018).

[14] M. Lorenzo, C. H. Crouch, and E. Mazur, Reducing the gender gap in the physics classroom, Am. J. Phys. 74, 118 (2006).
[15] S. J. Pollock, N. D. Finkelstein, and L. E. Kost, Reducing the gender gap in the physics classroom: How sufficient is interactive engagement?, Phys. Rev. Phys. Educ. Res. 3, 010107 (2007).

[16] E. Brewe, V. Sawtelle, L. H. Kramer, G.E. O'Brien, I. Rodriguez, and P. Pamelá, Toward equity through participation in modeling instruction in introductory university physics, Phys. Rev. Phys. Educ. Res. 6, 010106 (2010).

[17] G. Sonnert and M. F. Fox, Women, men, and academic performance in science and engineering: The gender difference in undergraduate grade point averages, J. Higher Educ. 83, 73 (2012).

[18] J. M. Nissen and J. T. Shemwell, Gender, experience, and self-efficacy in introductory physics, Phys. Rev. Phys. Educ. Res. 12, 020105 (2016).

[19] H. Fencl and K. Scheel, Research and teaching: Engaging students-an examination of the effects of teaching strategies on self-efficacy and course climate in a nonmajors physics course, J. Coll. Sci. Teach. 35, 20 (2005), https:// www.jstor.org/stable/42992548.

[20] C. Lindstrøm and M. D. Sharma, Self-efficacy of first year university physics students: Do gender and prior formal instruction in physics matter?, Int. J. Innov. Sci. Math Educ. 19, 1 (2011).

[21] J.S. Eccles, Understanding women's educational, and occupational choices: Applying the Eccles et al. model of achievement-related choices, Psychol. Women Q. 18, 585 (1994).

[22] R. Ivie and K. Stowe, Women in Physics, 2000, AIP report (AIP, New York, 2000).

[23] N. M. Hewitt and E. Seymour, A long, discouraging climb, ASEE Prism 1, 24 (1992).

[24] G. C. Marchand and G. Taasoobshirazi, Stereotype threat and women's performance in physics, Int. J. Sci. Educ. 35, 3050 (2013).

[25] K. R. Christy and J. Fox, Leaderboards in a virtual classroom: A test of stereotype threat and social comparison explanations for women's math performance, Comp. Educ. 78, 66 (2014).

[26] R. J. Rydell, R. M. Shiffrin, K. L. Boucher, K. Van Loo, and M.T. Rydell, Stereotype threat prevents perceptual learning, Proc. Natl. Acad. Sci. U.S.A. 107, 14042 (2010).

[27] A. Bandura, in Encyclopedia of Psychology, edited by R. J. Corsini (Wiley, New York, 1994), pp. 368-369.

[28] A. Bandura, Self-efficacy: Toward a unifying theory of behavioral change, Psychol. Rev. 84, 191 (1977).

[29] V. Sawtelle, E. Brewe, and L. H. Kramer, Exploring the relationship between self-efficacy and retention in introductory physics, J. Res. Sci. Teach. 49, 1096 (2012). 
[30] B. J. Zimmerman, Self-efficacy: An essential motive to learn, Contemp. Educ. Psychol. 25, 82 (2000).

[31] D. H. Schunk and F. Pajares, Development of Achievement Motivation (Elsevier, London, 2002), pp. 15-31.

[32] J. M. Bailey, D. Lombardi, J.R. Cordova, and G. M. Sinatra, Meeting students halfway: Increasing self-efficacy and promoting knowledge change in astronomy, Phys. Rev. Phys. Educ. Res. 13, 020140 (2017).

[33] S. L. Britner, Motivation in high school science students: A comparison of gender differences in life, physical, and earth science classes, J. Res. Sci. Teach. 45, 955 (2008).

[34] S. Cheryan, S. A. Ziegler, A. K. Montoya, and L. Jiang, Why are some STEM fields more gender balanced than others?, Psychol. Bull. 143, 1 (2017).

[35] M.-T. Wang and J. Degol, Motivational pathways to STEM career choices: Using expectancy-value perspective to understand individual and gender differences in STEM fields, Dev. Rev. 33, 304 (2013).

[36] E. Lichtenberger and C. George-Jackson, Predicting high school students' interest in majoring in a STEM field: Insight into high school students' postsecondary plans, J. Career Tech. Educ. 28, 19 (2013).

[37] A. C. Strenta, R. Elliott, R. Adair, M. Matier, and J. Scott, Choosing and leaving science in highly selective institutions, Res. High. Educ. 35, 513 (1994).

[38] J. M. Harackiewicz, K. E. Barron, J. M. Tauer, and A. J. Elliot, Predicting success in college: A longitudinal study of achievement goals and ability measures as predictors of interest and performance from freshman year through graduation, J. Educ. Psychol. 94, 562 (2002).

[39] S. Hidi, Interest: A unique motivational variable, Educ. Res. Rev. 1, 69 (2006).

[40] T. Kosiol, S. Rach, and S. Ufer, (which) mathematics interest is important for a successful transition to a university study program?, Int. J. Sci. Math. Educ. 17, 1359 (2019).

[41] P. Häussler and L. Hoffmann, An intervention study to enhance girls' interest, self-concept, and achievement in physics classes, J. Res. Sci. Teach. 39, 870 (2002).

[42] A. Wigfield and J. S. Eccles, Expectancy-value theory of achievement motivation, Contemp. Educ. Psychol. 25, 68 (2000).

[43] A. Wigfield and J. S. Eccles, The development of achievement task values: A theoretical analysis, Dev.Rev. 12, 265 (1992).

[44] R. H. Tai and P. M. Sadler, Gender differences in introductory undergraduate physics performance: University physics versus college physics in the USA, Int. J. Sci. Educ. 23, 1017 (2001).

[45] R. Henderson, G. Stewart, J. Stewart, L. Michaluk, and A. Traxler, Exploring the gender gap in the conceptual survey of electricity and magnetism, Phys. Rev. Phys. Educ. Res. 13, 020114 (2017).

[46] A. T. Wee, B.E. Baaquie, and A. C. Huan, Gender differences in undergraduate physics examination performance and learning strategies in Singapore, Phys. Educ. 28, 158 (1993).

[47] N. I. Karim, A. Maries, and C. Singh, Do evidence-based active-engagement courses reduce the gender gap in introductory physics?, Eur. J. Phys. 39, 025701 (2018).
[48] Z. Hazari, R. H. Tai, and P. M. Sadler, Gender differences in introductory university physics performance: The influence of high school physics preparation and affective factors, Sci. Educ. 91, 847 (2007).

[49] L. E. Kost, S. J. Pollock, and N. D. Finkelstein, Characterizing the gender gap in introductory physics, Phys. Rev. Phys. Educ. Res. 5, 010101 (2009).

[50] A. M. L. Cavallo, W. H. Potter, and M. Rozman, Gender differences in learning constructs, shifts in learning constructs, and their relationship to course achievement in a structured inquiry, yearlong college physics course for life science majors, School Sci. Math. 104, 288 (2004).

[51] R. M. Felder, G. N. Felder, M. Mauney, C. E. Hamrin Jr, and E. J. Dietz, A longitudinal study of engineering student performance and retention. III. Gender differences in student performance and attitudes, J. Eng. Educ. 84, 151 (1995).

[52] P. M. Sadler and R. H. Tai, Success in introductory college physics: The role of high school preparation, Sci. Educ. 85, 111 (2001).

[53] A. Madsen, S. B. McKagan, and E. C. Sayre, Gender gap on concept inventories in physics: What is consistent, what is inconsistent, and what factors influence the gap?, Phys. Rev. Phys. Educ. Res. 9, 020121 (2013).

[54] G. E. Hart and P. D. Cottle, Academic backgrounds and achievement in college physics, Phys. Teach. 31, 470 (1993).

[55] M. G. Jones, A. Howe, and M. J. Rua, Gender differences in students' experiences, interests, and attitudes toward science and scientists, Sci. Educ. 84, 180 (2000).

[56] S. L. Eddy and S. E. Brownell, Beneath the numbers: A review of gender disparities in undergraduate education across science, technology, engineering, and math disciplines, Phys. Rev. Phys. Educ. Res. 12, 020106 (2016).

[57] Z. Hazari, G. Sonnert, P. M. Sadler, and M.-C. Shanahan, Connecting high school physics experiences, outcome expectations, physics identity, and physics career choice: A gender study, J. Res. Sci. Teach. 47, 978 (2010).

[58] C. Monsalve, Z. Hazari, D. McPadden, G. Sonnert, and P. M. Sadler, Examining the relationship between career outcome expectations and physics identity, in Proceedings of the 2016 Physics Education Research Conference, Sacramento, CA (AIP, New York, 2016), pp. 228-231.

[59] S. Chen and B. Wei, Development and validation of an instrument to measure high school students' science identity in science learning, Res. Sci. Educ. 50, 1 (2020).

[60] J. E. Stets, P. S. Brenner, P. J. Burke, and R. T. Serpe, The science identity and entering a science occupation, Soc. Sci. Res. 64, 1 (2017).

[61] H. B. Carlone and A. Johnson, Understanding the science experiences of successful women of color: Science identity as an analytic lens, J. Res. Sci. Teach. 44, 1187 (2007).

[62] J. P. Gee, Chapter 3: Identity as an analytic lens for research in education, Rev. Res. Educ. 25, 99 (2000).

[63] P. Vincent-Ruz and C. D. Schunn, The nature of science identity and its role as the driver of student choices, Int. J. STEM Educ. 5, 48 (2018).

[64] L. B. Krogh and H. M. Andersen, "Actually, I may be clever enough to do it". Using identity as a lens to investigate students' trajectories towards science and university, Res. Sci. Educ. 43, 711 (2013). 
[65] Z. Hazari and C. Cass, Towards meaningful physics recognition: What does this recognition actually look like?, Phys. Teach. 56, 442 (2018).

[66] Z. Hazari, E. Brewe, R. M. Goertzen, and T. Hodapp, The importance of high school physics teachers for female students' physics identity and persistence, Phys. Teach. 55, 96 (2017).

[67] Z. Y. Kalender, E. Marshman, C. D. Schunn, T. J. NokesMalach, and C. Singh, Why female science, technology, engineering, and mathematics majors do not identify with physics: They do not think others see them that way, Phys. Rev. Phys. Educ. Res. 15, 020148 (2019).

[68] L. Archer, J. Moote, B. Francis, J. DeWitt, and L. Yeomans, The "exceptional" physics girl: A sociological analysis of multimethod data from young women aged $10-16$ to explore gendered patterns of post-16 participation, Am. Educ. Res. J. 54, 88 (2017).

[69] R. M. Lock, Z. Hazari, and G. Potvin, Physics career intentions: The effect of physics identity, math identity, and gender, AIP Conf. Proc. 1513, 262 (2013).

[70] A. Godwin, G. Potvin, Z. Hazari, and R. Lock, Identity, critical agency, and engineering: An affective model for predicting engineering as a career choice, J. Eng. Educ. 105, 312 (2016).

[71] Z. Y. Kalender, E. Marshman, C. D. Schunn, T. J. NokesMalach, and C. Singh, Gendered patterns in the construction of physics identity from motivational factors, Phys. Rev. Phys. Educ. Res. 15, 020119 (2019).

[72] S.-J. Leslie, A. Cimpian, M. Meyer, and E. Freeland, Expectations of brilliance underlie gender distributions across academic disciplines, Science 347, 262 (2015).

[73] S. Upson and L. F. Friedman, Where are all the female geniuses?, Sci. Am. Mind 23, 63 (2012).

[74] L. Bian, S.-J. Leslie, and A. Cimpian, Gender stereotypes about intellectual ability emerge early and influence children's interests, Science 355, 389 (2017).

[75] A. Zohar and A. Gershikov, Gender and performance in mathematical tasks: Does the context make a difference?, Int. J. Sci. Math. Educ. 6, 677 (2008).

[76] R. Masika and J. Jones, Building student belonging and engagement: Insights into higher education students' experiences of participating and learning together, Teaching Higher Educ. 21, 138 (2016).

[77] C. Goodenow, Classroom belonging among early adolescent students: Relationships to motivation and achievement, J. Early Adolesc. 13, 21 (1993).

[78] D. E. Meltzer and K. Manivannan, Transforming the lecture-hall environment: The fully interactive physics lecture, Am. J. Phys. 70, 639 (2002).

[79] D. Doucette, R. Clark, and C. Singh, Hermione and the Secretary: How gendered task division in introductory physics labs can disrupt equitable learning, Eur. J. Phys. 41, 035702 (2020).

[80] D. Doucette and C. Singh, Why are there so few women in physics? Reflections on the experiences of two women, Phys. Teach. 58, 297 (2020).
[81] S. M. Glynn, P. Brickman, N. Armstrong, and G. Taasoobshirazi, Science motivation questionnaire II: Validation with science majors and nonscience majors, J. Res. Sci. Teach. 48, 1159 (2011).

[82] PERTS academic mindsets assessment, https://survey.perts .net/share/dlmooc.

[83] E. M. Marshman, Z. Y. Kalender, C. Schunn, T. NokesMalach, and C. Singh, A longitudinal analysis of students' motivational characteristics in introductory physics courses: Gender differences, Can. J. Phys. 96, 391 (2018).

[84] Z. Hazari, G. Potvin, R. M. Lock, F. Lung, G. Sonnert, and P. M. Sadler, Factors that affect the physical science career interest of female students: Testing five common hypotheses, Phys. Rev. Phys. Educ. Res. 9, 020115 (2013).

[85] Activation lab tools: Measures and data collection instruments, http://www.activationlab.org/tools/.

[86] J. Schell and B. Lukoff, Peer Instruction Self-Efficacy Instrument [developed at Harvard University] (to be published) (2010).

[87] C. Singh, Impact of peer interaction on conceptual test performance, Am. J. Phys. 73, 446 (2005).

[88] R. Sayer, E. Marshman, and C. Singh, The impact of peer interaction on the responses to clicker questions in an upper-level quantum mechanics course, in Proceedings of the 2016 Physics Education Research Conference, Sacramento, CA (2016), pp. 304-307, 10.1119/ perc.2016.pr.071.

[89] R. Likert, A technique for the measurement of attitudes, Arch. Psychol. 22, 55 (1932).

[90] J. Cohen, Statistical Power Analysis for the Behavioral Sciences (Routledge, London, 2013).

[91] R. C. Team, R: A language and environment for statistical computing (2013).

[92] R. C. MacCallum, M. W. Browne, and H. M. Sugawara, Power analysis and determination of sample size for covariance structure modeling, Psychological Methods 1, 130 (1996).

[93] A. J. Tomarken and N. G. Waller, Structural equation modeling: Strengths, limitations, and misconceptions, Annu. Rev. Clin. Psychol. 1, 31 (2005).

[94] M. Meeuwisse, S. E. Severiens, and M. P. Born, Learning environment, interaction, sense of belonging and study success in ethnically diverse student groups, Res. High. Educ. 51, 528 (2010).

[95] S. M. Aguillon, G.-F. Siegmund, R. H. Petipas, A. G. Drake, S. Cotner, and C. J. Ballen, Gender differences in student participation in an active-learning classroom, $\mathrm{CBE}$ Life Sci. Educ. 19, 1 (2020).

[96] D. S. Yeager and G. M. Walton, Social-psychological interventions in education: They're not magic, Rev. Educ. Res. 81, 267 (2011).

[97] K. R. Binning, N. Kaufmann, E. M. McGreevy, O. Fotuhi, S. Chen, E. Marshman, Z. Yasemin Kalender, L. Limeri, L. Betancur, and C. Singh, Changing social norms to foster the benefits of collaboration in diverse workgroups, Psychol. Sci. 31, 1059 (2020). 